\title{
Phase Stability Diagrams for High Temperature Corrosion Processes
}

\author{
J. J. Ramos-Hernandez, ${ }^{1}$ J. Porcayo-Calderon, ${ }^{2}$ V. M. Salinas-Bravo, ${ }^{3}$ \\ C. D. Arrieta-Gonzalez, ${ }^{4}$ J. G. Gonzalez-Rodriguez, ${ }^{2}$ and L. Martinez-Gomez ${ }^{5}$ \\ ${ }^{1}$ Facultad de Química, Universidad Nacional Autónoma de México, 04510 México City, DF, Mexico \\ ${ }^{2}$ Centro de Investigación en Ingeniería y Ciencias Aplicadas, UAEM, Avenida Universidad 1001, Colonia Chamilpa, \\ 62210 Cuernavaca, MOR, Mexico \\ ${ }^{3}$ Instituto de Investigaciones Eléctricas, Gerencia de Materiales y Procesos Químicos, Avenida Reforma 113, Colonia Palmira, \\ 62490 Cuernavaca, MOR, Mexico \\ ${ }^{4}$ Instituto Tecnologico de Zacatepec, Departamento de Ingenieria Quimica y Bioquimica, Avenida Instituto Tecnologico 27, \\ 62780 Zacatepec, MOR, Mexico \\ ${ }^{5}$ Universidad Nacional Autonoma de Mexico, Instituto de Ciencias Fisicas, Avenida Universidad s/n, 62210 Cuernavaca, MOR, Mexico
}

Correspondence should be addressed to J. Porcayo-Calderon; jporcayoc@gmail.com

Received 20 February 2013; Accepted 29 May 2013

Academic Editor: Gianluca Ranzi

Copyright (C) 2013 J. J. Ramos-Hernandez et al. This is an open access article distributed under the Creative Commons Attribution License, which permits unrestricted use, distribution, and reproduction in any medium, provided the original work is properly cited.

Corrosion phenomena of metals by fused salts depend on chemical composition of the melt and environmental conditions of the system. Detail knowledge of chemistry and thermodynamic of aggressive species formed during the corrosion process is essential for a better understanding of materials degradation exposed to high temperature. When there is a lack of kinetic data for the corrosion processes, an alternative to understand the thermodynamic behavior of chemical species is to utilize phase stability diagrams. Nowadays, there are several specialized software programs to calculate phase stability diagrams. These programs are based on thermodynamics of chemical reactions. Using a thermodynamic data base allows the calculation of different types of phase diagrams. However, sometimes it is difficult to have access to such data bases. In this work, an alternative way to calculate phase stability diagrams is presented. The work is exemplified in the Na-V-S-O and Al-Na-V-S-O systems. This system was chosen because vanadium salts is one of the more aggressive system for all engineering alloys, especially in those processes where fossil fuels are used.

\section{Introduction}

Equilibrium calculations show whether a chemical or electrochemical reaction may proceed or not. No information is given about the rate of the reaction, that is, its kinetics. However, increasing temperature and thereby usually faster reaction rates, cause diagrams based on only thermodynamic considerations to be more relevant.

In a phase stability diagram of predominant area, the area of stability of a chemical species is delimited by lines of equilibrium in which the value of the Gibbs free energy is zero. The characteristics of such lines (slope and ordinate to the origin) are based on chemical reactions where the chemical species is present as a reactant or product, since his area of stability may be surrounded by the area of stability of other chemical species which are also involved in reaction (closed stability area) or the area may be defined only at one side and open towards infinite stability conditions (open stability area).

For definition of equilibrium lines in a phase stability diagram, a chemical system is treated mathematically as a set of equations where each chemical reaction corresponds to a mathematical equation, equating to zero the sum of the Gibbs free energies of the chemicals species in each reaction.

Although there is specialized software in calculating phase stability diagrams, sometimes arises a need to develop 
TABLE 1: Reactions for the phase stability diagram of Si-O system at $1400 \mathrm{~K}$.

\begin{tabular}{cccc}
\hline$\#$ & Reaction & Log $K$ & Type of equilibrium line \\
\hline 1 & $\mathrm{Si}(\mathrm{s})+\mathrm{O}_{2}=\mathrm{SiO}_{2}(\mathrm{~s})$ & 24.66 & $\mathrm{~A}$ \\
2 & $\mathrm{Si}(\mathrm{s})=\mathrm{Si}$ & -9.08 & $\mathrm{~B}$ \\
3 & $2 \mathrm{Si}(\mathrm{s})+\mathrm{O}_{2}=2 \mathrm{SiO}$ & 16.26 & $\mathrm{C}$ \\
4 & $\mathrm{Si}+\mathrm{O}_{2}=\mathrm{SiO}_{2}(\mathrm{~s})$ & 33.74 & $\mathrm{C}$ \\
5 & $2 \mathrm{SiO}+\mathrm{O}_{2}=2 \mathrm{SiO}_{2}(\mathrm{~s})$ & 33.06 & $\mathrm{C}$ \\
\hline
\end{tabular}

one step by step. When have the necessary thermochemical data, the definition of lines for each reaction equilibrium is not difficult; however, to define the area of stability of a given chemical species when the number of reactions to consider increases is a complicated task.

In this work a methodology has been proposed to calculate the stability phase diagrams [1]. Fundamentals are based on the search of triple points by analyzing the stoichiometric relationship of reactants and products in all chemical reactions that define the system. This avoids complicated calculation as in the simplex method [2] where the search of every stability area for each one of the chemical compounds must be calculated.

At present, the system has 1805 records of chemical compounds. Each compound has information of the nine NASA coefficients [3-5] for a specific temperature range. This enables calculation of thermochemical properties of every compound and equilibrium lines of chemical reactions. This data is taken as the input data for calculating the phase stability diagrams for the method proposed.

\section{Materials and Methods}

2.1. Constructing Diagrams with Predominant Area. Construction of phase stability diagrams begins by selecting those chemical elements that will form species (compounds) whose stability area is of interest, that is, $\mathrm{Si}$ and O. Later on, it is necessary to define the interaction of such species (compounds) by chemical reactions, establishing stoichiometric coefficients as presented in Table 1, such that certain chemical specie (specie i) can be found in one or in all chemical reactions. Such reactions represent the equilibrium border lines that define the stability area of specie $i$.

Afterwards, chemical species that will represent $X$ and $Y$ axes in the phase diagram must be selected. It is important to note that at least one of the species selected must be present in all chemical reactions without exception, that is, $\mathrm{O}_{2}, \mathrm{Si}$, or $\mathrm{SiO}$.

From this information, we can define the type of equilibrium border line of a particular chemical reaction. Figure 1 represents the $\mathrm{Si}-\mathrm{O}$ diagram at $1400 \mathrm{~K}$ obtained by the proposed method. This diagram is taken as an example for defining types of equilibrium border line. In such diagram, the $X$ axis represents the logarithm of oxygen partial pressure, and the $Y$ axis represents the logarithm of silicon and silicon oxide $(\mathrm{Si}, \mathrm{SiO})$ partial pressure.

An equilibrium line will be parallel to the $Y$ axis (type A) only when the species representing the $Y$ axis in the chemical

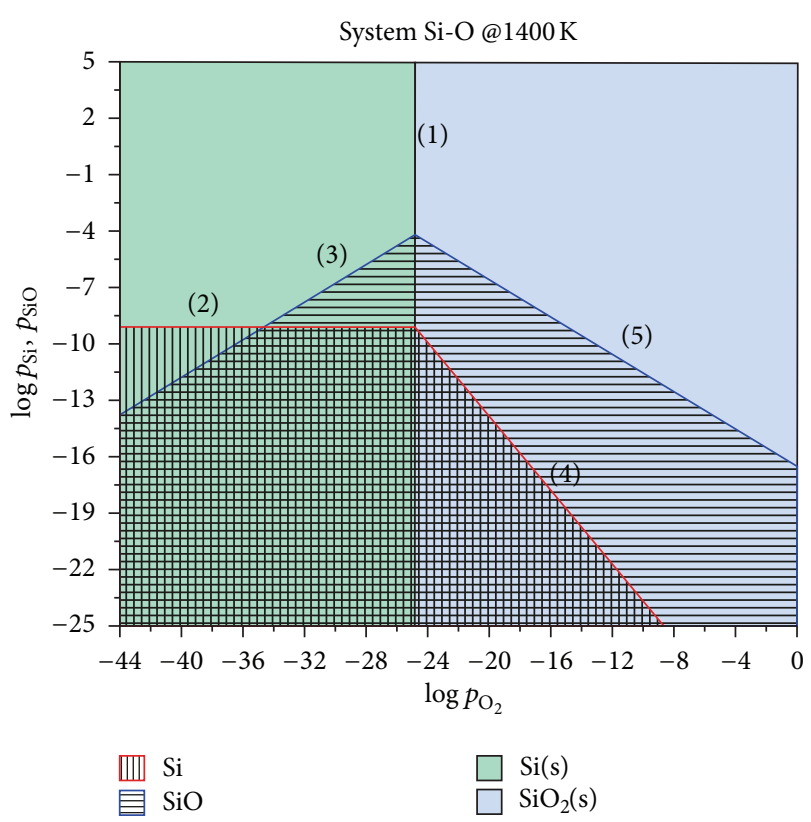

FIgure 1: Phase stability diagram of Si-O system at $1400 \mathrm{~K}$. Numbers correspond to the reactions showed in Table 1.

reaction does not exist and the species that represents the $X$ axis exists, that is, reaction (1), where the $\mathrm{O}_{2}$ that represents the $X$ axis is present. This reaction defines the area stability of solid species $\mathrm{Si}(\mathrm{s})$ and $\mathrm{SiO}_{2}(\mathrm{~s})$.

By contrast, an equilibrium line will be parallel to the $X$ axis having a slope equal to zero (type B), only when the species representing the $X$ axis does not exist in the chemical reaction and the species representing the $Y$ axes exists, that is, reaction (2). An equilibrium line with a slope greater than zero (type $\mathrm{C}$ ) means that between products and reactants there is one species representing $X$ axis and one representing $Y$ axis as illustrated by reactions (3), (4), and (5). Slope and origin ordinate concepts only apply to equilibrium lines represented by (2) and (3), so a parallel line to $Y$ axis can be identified by knowing the $X$ value.

Values in Figure 1 depend on thermochemical properties of chemical species in the chemical reaction involved. As an example, calculations are presented in order to define the equilibrium lines for every reaction presented in Table 1 . In this example, the $\log K$ values showed in Table 1 and the activity of condensed species equal to 1 have been considered [6].

For reaction (1):

$$
\begin{aligned}
\log K_{\text {Reaction } 1} & =\log a_{\mathrm{SiO}_{2}(\mathrm{~s})}-\log a_{\mathrm{Si}(s)}-\log p_{\mathrm{O}_{2}}, \\
& 24.66=-\log p_{\mathrm{O}_{2}} \\
& \log p_{\mathrm{O}_{2}}=-24.66
\end{aligned}
$$

A line parallel to the $Y$ axis (type A) will be drawn crossing the $X$ axis value at -24.66 . 
For reaction (2):

$$
\begin{gathered}
\log K_{\text {Reaction } 2}=\log a_{\mathrm{Si}(\mathrm{s})}-\log p_{\mathrm{Si}}, \\
-9.08=-\log p_{\mathrm{Si}}, \\
\log p_{\mathrm{Si}}=9.08 .
\end{gathered}
$$

A line parallel to the $X$ axis (type B) will be drawn crossing the $Y$ axis value at 9.08 .

For reaction (3):

$$
\begin{gathered}
\log K_{\text {Reaction } 3}=2 \log p_{\mathrm{SiO}}-2 \log a_{\mathrm{Si}(\mathrm{s})}-\log p_{\mathrm{O}_{2}}, \\
16.26=2 \log p_{\mathrm{SiO}}-\log p_{\mathrm{O}_{2}}, \\
\log p_{\mathrm{SiO}}=\frac{16.26+\log p_{\mathrm{O}_{2}}}{2}, \\
\log p_{\mathrm{SiO}}=0.5 \cdot \log p_{\mathrm{O}_{2}}+8.13 .
\end{gathered}
$$

A line with slope of 0.5 and origin ordinate of 8.13 (type C) will be drawn.

For reaction (4):

$$
\begin{gathered}
\log K_{\text {Reaction } 4}=\log a_{\mathrm{SiO}_{2}(\mathrm{~s})}-\log p_{\mathrm{Si}}-\log p_{\mathrm{O}_{2}}, \\
33.74=-\log p_{\mathrm{Si}}-\log p_{\mathrm{O}_{2}}, \\
\log p_{\mathrm{Si}}=-\log p_{\mathrm{O}_{2}}-33.74 .
\end{gathered}
$$

A line with slope of -1 and origin ordinate of -33.74 (type C) will be drawn.

For reaction (5):

$$
\begin{gathered}
\log K_{\text {Reaction } 4}=2 \log a_{\mathrm{SiO}_{2}(\mathrm{~s})}-2 \log p_{\mathrm{SiO}}-\log p_{\mathrm{O}_{2}}, \\
33.06=-2 \log p_{\mathrm{SiO}}-\log p_{\mathrm{O}_{2}}, \\
\log p_{\mathrm{SiO}}=\frac{-\log p_{\mathrm{O}_{2}}-33.06}{2}, \\
\log p_{\mathrm{SiO}}=-0.5 \cdot \log p_{\mathrm{O}_{2}}-16.53 .
\end{gathered}
$$

A line with slope of -0.5 and origin ordinate of -16.53 (type C) will be drawn.

Knowing that equilibrium lines in a phase stability diagram define conditions where the free energy of formation in a chemical reaction is zero, it can be stated that the intersection point of two equilibrium lines indicates that both reactions are in equilibrium. This is the first guideline to establish that in such point, there exists a possible vertex of a polygon that defines a stability area of a substance.

In order to confirm the existence of a vertex in an intersection, several stability diagrams reported in the literature [723 ] were analyzed. From this analysis, it was concluded that there must exist a third chemical reaction whose intersection point with the first two reactions is common. Besides, it should contain any chemical species that is found only in one of the two chemical reactions. It is important to mention that chemical species satisfying these criteria are the only ones that must be present in the third chemical reaction, together with one or both chemical species that represent a value in the phase stability diagram axes.

For example, for reactions (3) and (5), SiO defines the stability area. Reaction (3) contains species $\mathrm{Si}(\mathrm{s})$ which is not in reaction (5). Reaction (5) contains species $\mathrm{SiO}_{2}(\mathrm{~s})$ which is not in reaction (3); therefore, the reaction that defines an apex formed by intersections of reactions (3) and (5) must contain some of the species that define the axes as well as species $\mathrm{Si}(\mathrm{s})$ and $\mathrm{SiO}_{2}(\mathrm{~s})$. Consequently, the reaction satisfying such condition is only reaction (1).

For another example, it can be stated that the intersection between equilibrium lines of reactions (1), (2) that defines the stability of specie $\mathrm{Si}(\mathrm{s})$ is found in an apex. It can be seen that species $\mathrm{SiO}_{2}(\mathrm{~s}), \mathrm{Si}$, and $\mathrm{O}_{2}$ fulfill the criteria. For the third reaction, there must be present species $\mathrm{SiO}_{2}(\mathrm{~s})$ and necessarily $\mathrm{Si}$ and $\mathrm{O}_{2}$ species which represent axes in the graph. Reaction (4) fulfills with the premise mentioned before, so such reaction has a common intersection point.

Intersection between two equilibrium lines is easy to determine. When two lines cross each other it means they have a common point. This point verifies the equation of both lines. The problem is to find out this point. Let us suppose that we have the equation of both lines as follows:

$$
\begin{aligned}
& \text { Line 1: } y_{1}=m_{1} x+b_{1}, \\
& \text { Line 2: } y_{2}=m_{2} x+b_{2} .
\end{aligned}
$$

If there is one point $\left(x_{i}, y_{i}\right)$ that is shared by both lines, so (6) and (7) will be true. Solving for $y_{i}$, we have

$$
m_{1} x_{i}+b_{1}=m_{2} x_{i}+b_{2}
$$

Solving for $x_{i}$, we have

$$
x_{i}=\frac{b_{2}-b_{1}}{m_{1}-m_{2}} .
$$

Substituting this value either in (6) or (7), results (10)

$$
y_{i}=\frac{b_{2} m_{1}-b_{1} m_{2}}{m_{1}-m_{2}} .
$$

Therefore, the intersection point will have coordinates

$$
\left(\frac{b_{2}-b_{1}}{m_{1}-m_{2}}, \frac{b_{2} m_{1}-b_{1} m_{2}}{m_{1}-m_{2}}\right) \text {. }
$$

For example, intersection of (3) and (5) can be obtained from (11):

$$
\begin{gathered}
\left(\frac{-16.53-8.13}{0.5-(-0.5)}, \frac{(-16.53)(0.5)-(8.13)(-0.5)}{0.5-(-0.5)}\right) \\
\left(\frac{-24.66}{1}, \frac{-8.265-(-4.065)}{1}\right) \\
(-24.66,-4.2) .
\end{gathered}
$$

Coordinate $\left(x_{i}, y_{i}\right)$ obtained corresponds directly with the value at the equilibrium line of (1), revealing the location of a triple point. 


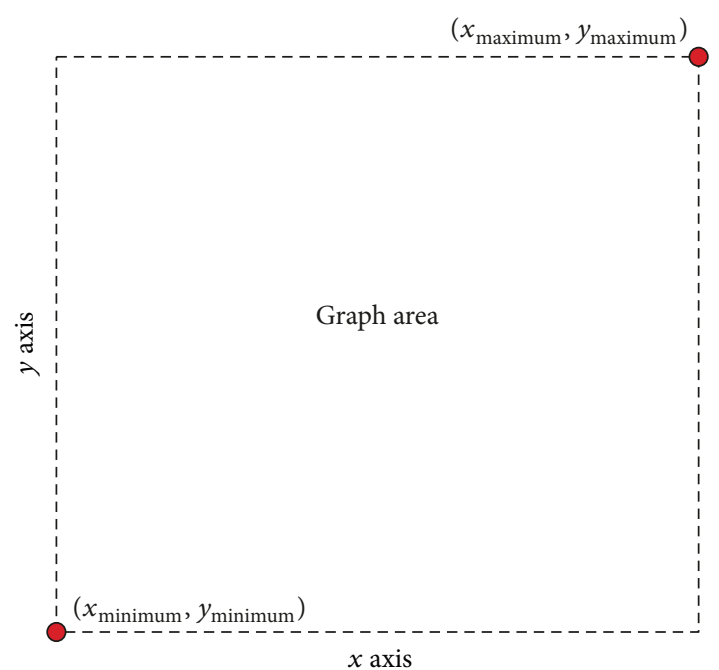

FIGURE 2: Graph area restricted by two points.

Knowing the number of points where there is a vertex (triple points), now, it is necessary to know how to use them to draw each equilibrium line in the phase stability diagram. The "area of graph" concept is now introduced. The "area graph" is described as the area where the equilibrium lines will be drawn in the phase equilibrium diagram. This area is restricted by two points $\left(X_{\min }, Y_{\min }\right)$ and $\left(X_{\max }, Y_{\max }\right)$ as is shown in Figure 2.

In a graph, a line is described by two points. Knowing the number of triple points in a line the following methodology can be adopted to define initial and final points in an equilibrium line.

(i) Initial point will be $\left(X_{\min }, f\left(X_{\min }\right)\right)$, and final point will be $\left(X_{\max }, f\left(X_{\max }\right)\right)$. This applies only to equations with known slope and origin ordinate. In case the lines are parallel to $Y$ axis, it is necessary to know the $X$ axis value where $\left(X_{i}\right)$ is found. In this case, the initial and final points will be $\left(X_{i}, Y_{\min }\right),\left(X_{i}, Y_{\max }\right)$, respectively.

(ii) In case an equilibrium line has two triple points or more, initial and final points have no change and remain as mentioned above.

(iii) If one equilibrium line has exactly two triple points, such points define equilibrium, considering that the $X$ value in the initial point must be smaller than the $X$ value in the final point (in lines with slopes and origin ordinates well defined) and the $Y$ value in the initial point must be smaller than the $Y$ value in the final point (for parallel lines to the $Y$ axis).

(iv) If in one equilibrium line there is only one triple point $\left(X_{e}, Y_{e}\right)$, we need to know if this point corresponds to the first or the last point. This is possible verifying the stability of some chemical species found in the chemical reaction which equilibrium is defined by such a line. Conditions set for defining initial point and value of Gibbs free energy have to be considered. If a chemical compound is stable in the initial point,

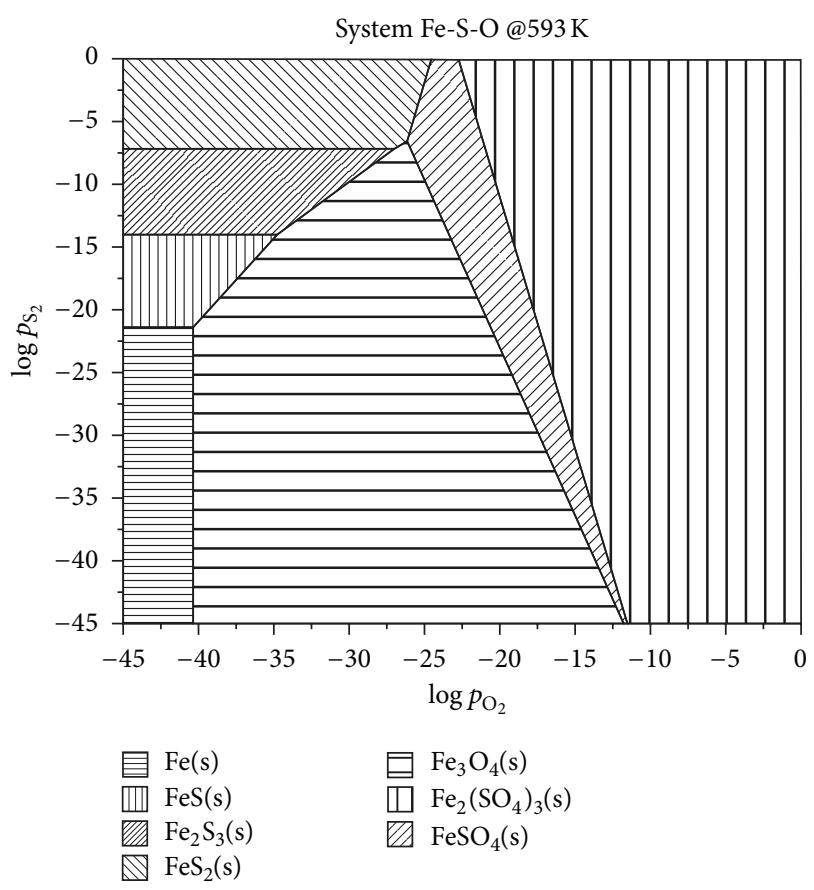

FIgURE 3: Phase stability diagram of Fe-S-O at $593 \mathrm{~K}$.

then the triple point $\left(X_{e}, Y_{e}\right)$ is the final point in the line, otherwise, it is the initial point.

\section{Results and Discussion}

3.1. Methodology Validation. Based on the methodology described previously, a web-based application was developed (PHP/MySQL). Using this application some phase stability diagrams were created and compared with those published in the literature. As an example, Figure 3 shows the Fe$\mathrm{S}-\mathrm{O}$ phase stability diagram obtained by the PHP/MySQL application.

Comparing the phase stability diagram shown in Figure 3 with that published by Behrani and Singh [24], it can be seen that both phase stability diagrams have the same features and stability areas.

It is important to consider that stability areas depend heavily on the chemical reactions considered to define them. For example, the diagram of Figure 3 considers only the area of stability of $\mathrm{Fe}_{3} \mathrm{O}_{4}(\mathrm{~s})$. However, the diagram of Figure 4 also shows the areas of stability of the oxides $\mathrm{FeO}(\mathrm{s})$ and $\mathrm{Fe}_{2} \mathrm{O}_{3}(\mathrm{~s})$. By comparing both figures, we can see that the inclusion of these oxides modify the area of stability of sulfides FeS(s), $\mathrm{Fe}_{2} \mathrm{~S}_{3}(\mathrm{~s})$, and $\mathrm{FeS}_{2}(\mathrm{~s})$.

Figure 5 shows the Na-V-S-O phase diagram obtained at $1173 \mathrm{~K}$ using the PHP/MySQL application. Comparing this diagram with the one published by Longa-Nava et al. [25], it can be seen that there are minor differences in the value of phase boundary lines crossing the $X$ and $Y$ axes. This difference arises because thermodynamic data of compounds can vary, depending on the data base source taken for calculating the diagram. 


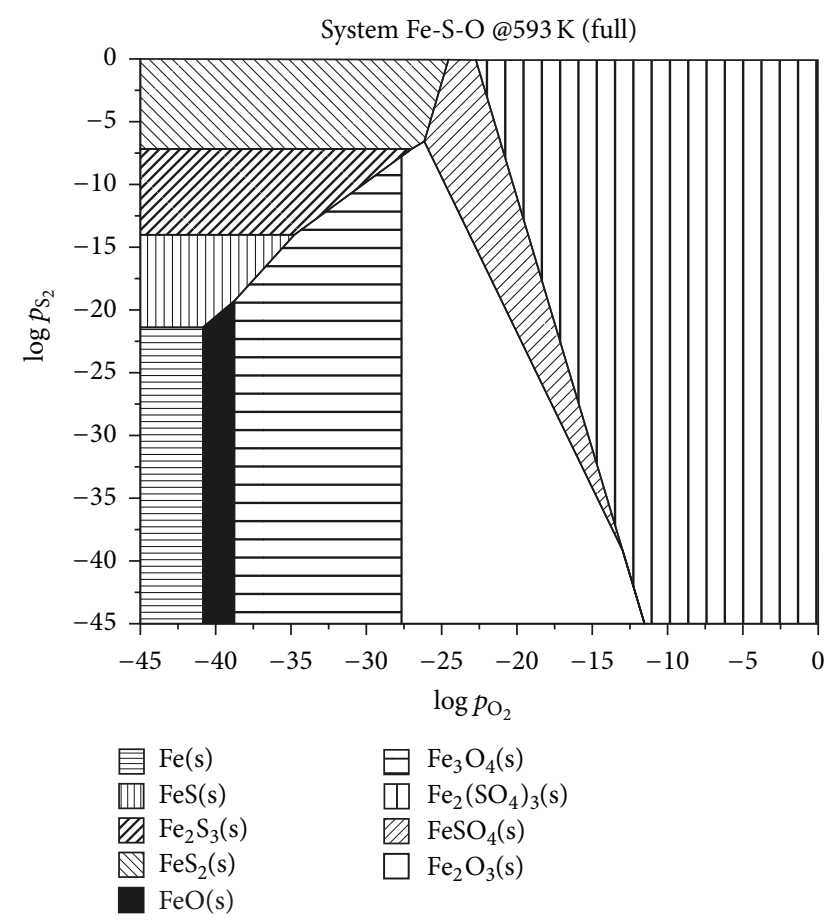

Figure 4: Phase stability diagram of Fe-S-O at $593 \mathrm{~K}$ with $\mathrm{FeO}(\mathrm{s})$ and $\mathrm{Fe}_{2} \mathrm{O}_{3}(\mathrm{~s})$ stability areas.

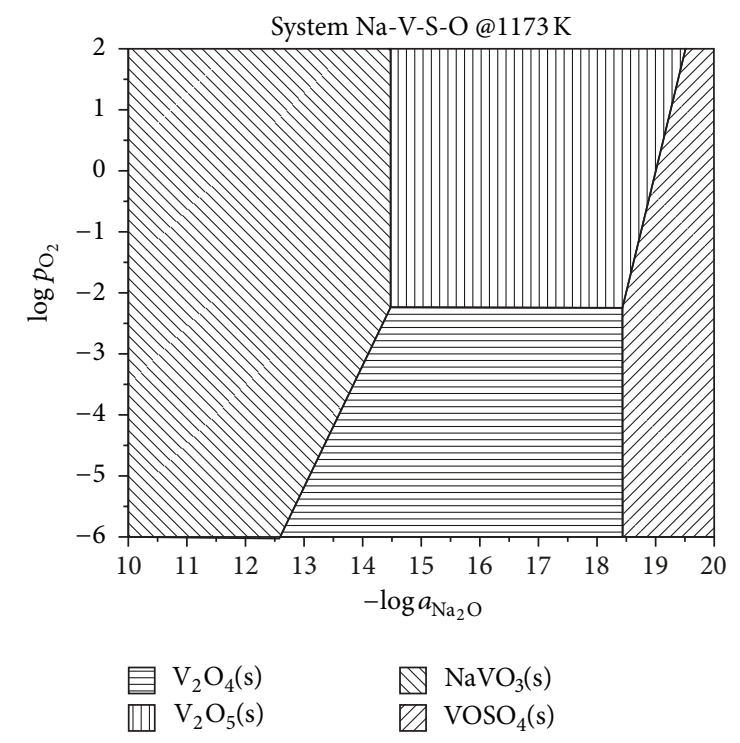

Figure 5: Phase stability diagram of Na-V-S-O at $1173 \mathrm{~K}$.

Figure 6 shows the previous phase stability diagram but including a wider range for $\log P_{\mathrm{O}_{2}}$ and $-\log a_{\mathrm{Na}_{2} \mathrm{O}}$ values. The diagram displays the entire range of vanadium oxides and sodium vanadate, showing the consistency of the methodology proposed for the development of the diagram.

Formation of sodium vanadate can take place in solidsolid or solid-liquid reactions because certain products and reactants have different melting points which vary with temperature. Rapp [12] indicates that basicity of melts can be

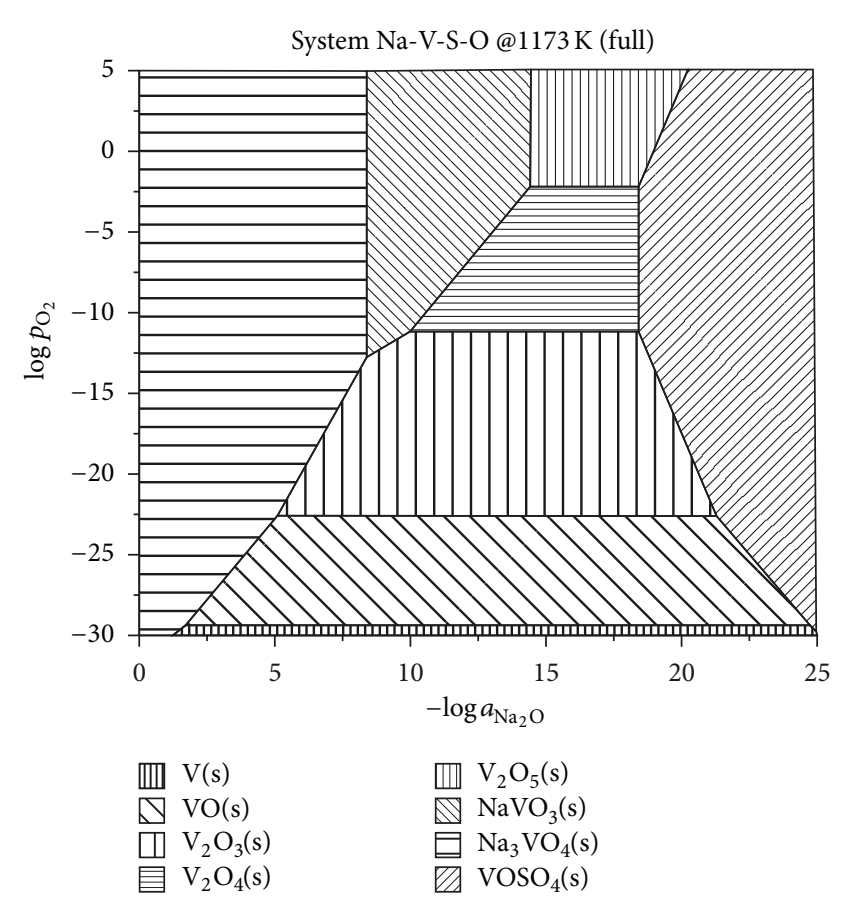

FIgure 6: Phase stability diagram of Na-V-S-O at $1173 \mathrm{~K}$.

measured by using solid-state electrodes. In this case, basicity is defined as $-\log a_{\mathrm{Na}_{2} \mathrm{O}}$ and is function of oxygen partial pressure. In this way, the solubility of several protective oxides is determined as a function of basicity.

One reaction describing the formation of metallic vanadate is that of a metallic oxide and $\mathrm{V}_{2} \mathrm{O}_{5}$; however, this reaction does not depend on basicity neither on oxygen partial pressure, so it cannot be represented by a stability phase diagram of the $\mathrm{Na}-\mathrm{V}-\mathrm{S}-\mathrm{O}$ system.

A metallic oxide is able to react with $\mathrm{NaVO}_{3}$ or with $\mathrm{Na}_{3} \mathrm{VO}_{4}$; therefore, the reaction product will be a metallic vanadate and $\mathrm{Na}_{2} \mathrm{O}$. Considering the reaction of the metallic oxide with $\mathrm{V}_{2} \mathrm{O}_{4}$ and oxygen, it is possible to represent such reactions in a stability phase diagram in the $\mathrm{M}-\mathrm{Na}-\mathrm{V}-\mathrm{S}-\mathrm{O}$ system. As an example, the Al-Na-V-S-O system obtained by using the PHP/MySQL application is presented.

Figure 7 shows the Al-Na-V-S-O phase diagram at $1173^{\circ} \mathrm{K}$. This type of diagram is not cited in the literature. Compared to Figure 6, this diagram allows to see that the area of stability of aluminum vanadate $\left(\mathrm{AlVO}_{4}(\mathrm{~s})\right)$ completely covers the area of stability $\mathrm{NaVO}_{3}(\mathrm{~s})$ and oxides of vanadium $\mathrm{V}_{2} \mathrm{O}_{4}(\mathrm{~s})$ and $\mathrm{V}_{2} \mathrm{O}_{5}(\mathrm{~s})$. It is also possible to observe that the stability area of $\mathrm{Al}_{2} \mathrm{O}_{3}(\mathrm{~s})$ is restricted to basic conditions, which strengthens the fact that this oxide is not protective in vanadium salts with acidic conditions.

Generally, the phase stability diagrams produced by the proposed methodology were in good agreement with those previously reported in the literature. In some diagrams, minor differences were found. Differences can be explained by the fact that thermodynamic data values can vary, depending on the data source. Some data bases are updated regularly 


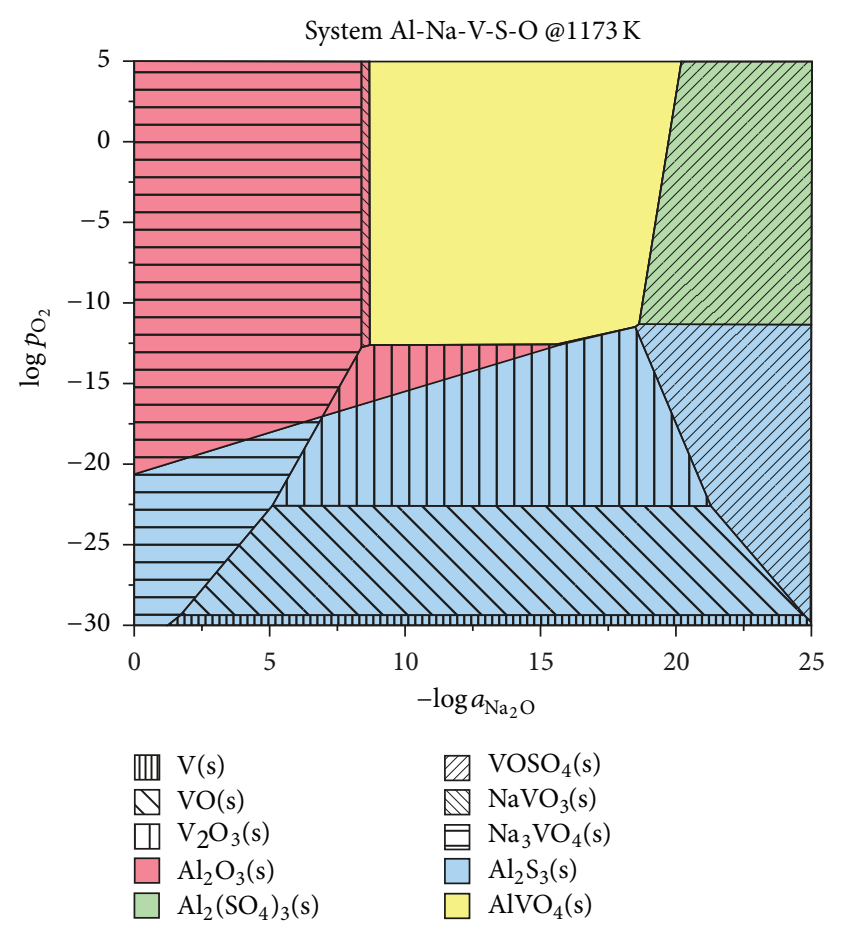

Figure 7: Phase stability diagram of Al-Na-V-S-O at $1173 \mathrm{~K}$.

and some take some time for updating its thermodynamic values reported.

\section{Conclusions}

The proposed methodology allows knowing the vertices of the area of stability of a species before carrying out a complex calculation, simply visualizing the reactants and products in those chemical reactions that appear.

The method proposed proved to produce reliable phase stability diagrams. The advantage of this method avoids complicated calculations to establish stability areas of a particular compound. This simplifies the process for calculating phase stability diagrams and avoids the need for developing complicated computer algorithms to produce phase stability diagrams.

The proposed method is consistent because the diagrams generated are same to those reported in the literature. Independently from the chemical reactions selected for the calculation of a diagram, the proposed approach is consistent.

\section{Acknowledgment}

Financial support from Consejo Nacional de Ciencia y Tecnología (CONACYT, México) (Project 49755 and Ph.D. scholarship to J. J. Ramos-Hernandez. registration no. 202898) is gratefully acknowledged.

\section{References}

[1] J. J. Ramos-Hernandez, Análisis termoquímico del sistema V-Na-S-O-M y su aplicación en el proceso de corrosión a alta temperatura [MSc dissertation], Universidad Nacional Autónoma de México, DF, Mexico, 2009.

[2] C. R. Wang, Z. B. Zhao, S. K. Xia, W. Q. Zhang, and R. Z. Zhu, "The computer algorithm and program for the generation of phase stability diagrams," Calphad, vol. 14, no. 3, pp. 257-264, 1990.

[3] B. J. McBride, S. Gordon, and M. A. Reno, "Coefficients for calculating thermodynamic and transport properties of individual species," NASA/TM 4513, 1993.

[4] B. J. McBride, M. J. Zehe, and S. Gordon, "NASA GLENN coefficients for calculating thermodynamic properties of individual species," NASA/TP-2002-211556, 2002.

[5] A. Burcat and B. Ruscic, "Third millennium ideal gas and condensed phase thermochemical database for combustion," Tech. Rep. DOE/MC, U.S. Depatment of Energy, 2005.

[6] J. Porcayo-Calderon, Protección contra corrosión a alta temperatura por medio de recubrimientos base silicio aplicados por proyección térmica [PhD dissertation], Universidad Nacional Autónoma de México, DF, Mexico, 1998.

[7] S. A. Jansson and E. A. Gulbransen, "Evaluation of gas-metal reactions by means of thermochemical diagrams," in Proceedings of the 4th International congress on metallic corrosion, pp. 331-335, 1969.

[8] E. A. Gulbransen and S. A. Jansson, "Vaporization chemistry in the oxidation of Carbon, Silicon, Chromium, Molybdenum and Niobium. Heterogeneous kinetics at elevated temperatures," in Proceedings of the International Conference in Metallurgy and Materials Science, pp. 181-208, 1969.

[9] P. Barret, Reaction Kinetics in Heterogeneous Chemical Systems, Chapter Relationships between Thermochemical and Kinetic Aspect of High Temperature Gas-Solid Reactions, Elsevier, San Diego, Calif, USA, 1975.

[10] M. Susa and K. Nagata, "Thermal oxidation of silicon substrates through oxygen diffusion," Materials Science and Engineering A, vol. 146, no. 1-2, pp. 51-62, 1991.

[11] P. J. Bellina, A. Catanoiu, F. M. Morales, and M. Rühle, "Formation of discontinuous $\mathrm{Al}_{2} \mathrm{O}_{3}$ layers during high-temperature oxidation of RuAl alloys," Journal of Materials Research, vol. 21, no. 1, pp. 276-286, 2006.

[12] R. A. Rapp, "Some generalities in the analyses of equilibria in ionic solutions," Metallurgical and Materials Transactions A, vol. 31, no. 9, pp. 2105-2118, 2000.

[13] R. A. Rapp, "Chemistry and electrochemistry of hot corrosion of metals," Materials Science and Engineering, vol. 87, pp. 319327, 1987.

[14] Y. S. Li, M. Spiegel, and S. Shimada, "Corrosion behaviour of various model alloys with $\mathrm{NaCl}-\mathrm{KCl}$ coating," Materials Chemistry and Physics, vol. 93, no. 1, pp. 217-223, 2005.

[15] A. Ruh and M. Spiegel, "Thermodynamic and kinetic consideration on the corrosion of $\mathrm{Fe}, \mathrm{Ni}$ and $\mathrm{Cr}$ beneath a molten $\mathrm{KCl}$ $\mathrm{ZnCl}_{2}$ mixture," Corrosion Science, vol. 48, no. 3, pp. 679-695, 2006.

[16] M. A. Uusitalo, P. M. J. Vuoristo, and T. A. Mäntylä, "High temperature corrosion of coatings and boiler steels below chlorine-containing salt deposits," Corrosion Science, vol. 46, no. 6, pp. 1311-1331, 2004.

[17] H. J. Grabke, E. Reese, and M. Spiegel, "The effects of chlorides, hydrogen chloride, and sulfur dioxide in the oxidation of steels below deposits," Corrosion Science, vol. 37, no. 7, pp. 1023-1043, 1995. 
[18] J.-W. Kwon, Y.-Y. Lee, and Y.-D. Lee, "Mechanisms of simultaneous oxidation-chloridation of austenitic stainless steels by $\mathrm{NaCl}$ in air," Materials at High Temperatures, vol. 17, no. 2, pp. 319-326, 2000.

[19] N. S. Bornstein, M. A. DeCrescente, and H. A. Roth, "The relationship between relative oxide ion content of $\mathrm{Na}_{2} \mathrm{SO}_{4}$, the presence of liquid metal oxides and sulfidation attack," Metallurgical Transactions, vol. 4, no. 8, pp. 1799-1810, 1973.

[20] W. H. Lee and R. Y. Lin, "Oxidation, sulfidation and hot corrosion of intermetallic compound $\mathrm{Fe}_{3} \mathrm{Al}$ at $605^{\circ} \mathrm{C}$ and $800^{\circ} \mathrm{C}$," Materials Chemistry and Physics, vol. 58, no. 3, pp. 231-242, 1999.

[21] F. Y. Gesmundo and F. Viani, "Corrosion of FeAl intermetallics in coal gasifications atmospheres," Materials For Advanced Power Engineering II, pp. 1657-1667, 1994.

[22] J. E. Hammer, S. J. Laney, R. W. Jackson, K. Coyne, F. S. Pettit, and G. H. Meier, "The oxidation of ferritic stainless steels in simulated solid-oxide fuel-cell atmospheres," Oxidation of Metals, vol. 67, no. 1-2, pp. 1-38, 2007.

[23] P. J. Spencer and I. Barin, "Computer-generated phase diagrams," International Journal of Materials in Engineering Applications, vol. 1, no. 3, pp. 167-179, 1979.

[24] V. Behrani and P. M. Singh, "Fluctuating sulfidizing-oxidizing environments and their effect on stability of protective scales on carbon steel," Corrosion, vol. 64, no. 12, pp. 883-890, 2008.

[25] Y. Longa-Nava, Y. S. Zhang, M. Takemoto, and R. A. Rapp, "Hot corrosion of nickel-chromium and nickel-chromiumaluminum thermal-spray coatings by sodium sulfate-sodium metavanadate salt," Corrosion, vol. 52, no. 9, pp. 680-689, 1996. 


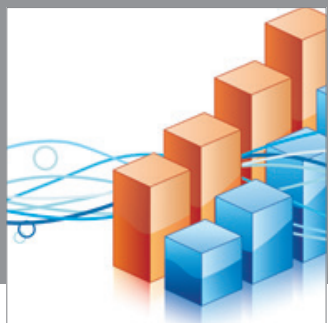

Advances in

Operations Research

mansans

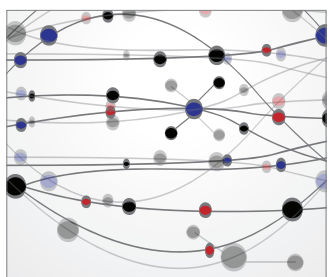

The Scientific World Journal
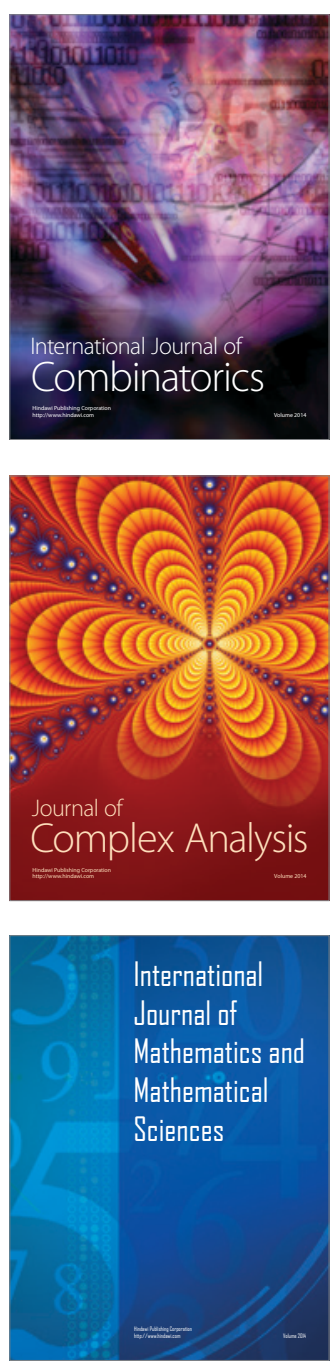
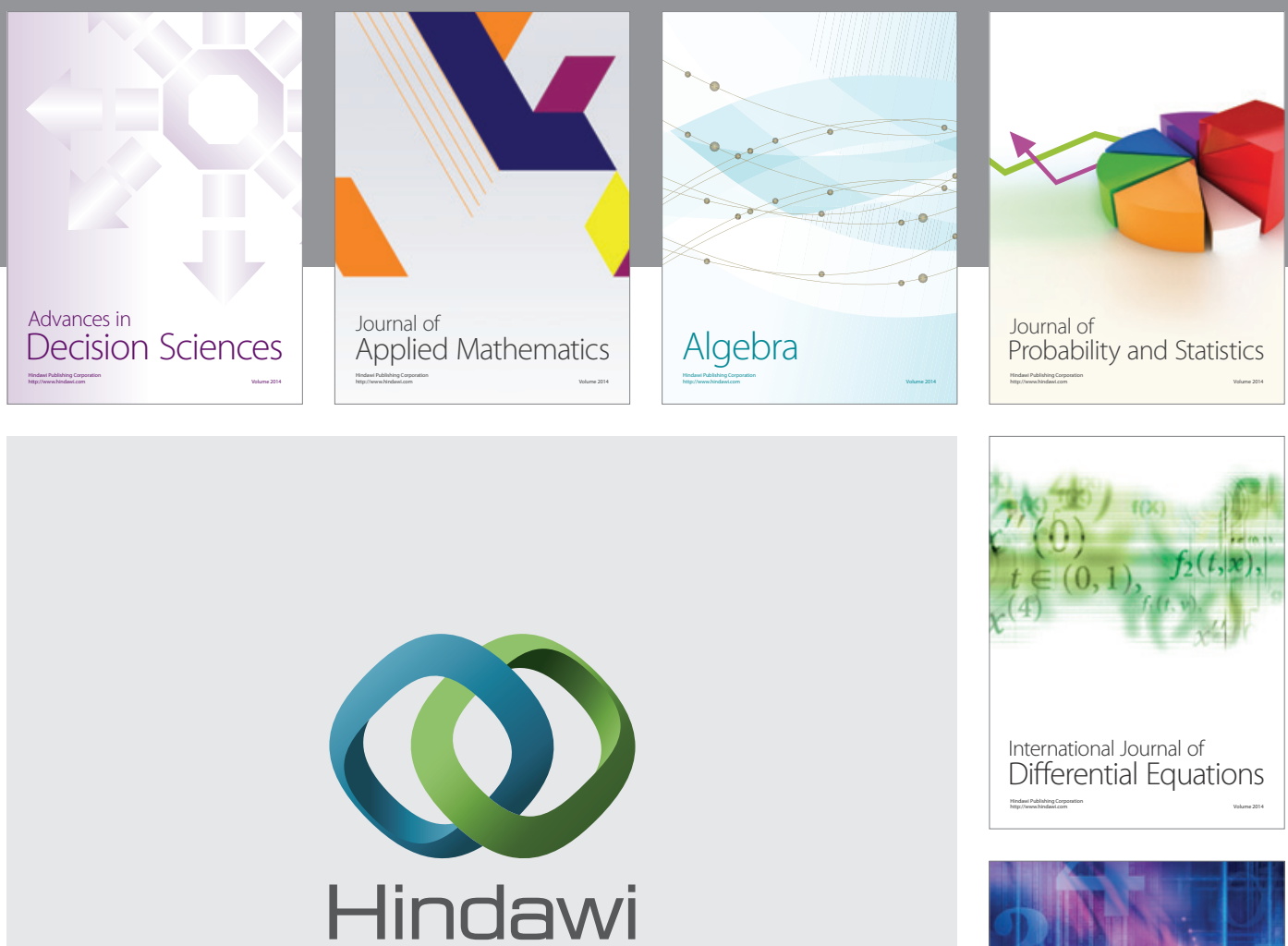

Submit your manuscripts at http://www.hindawi.com
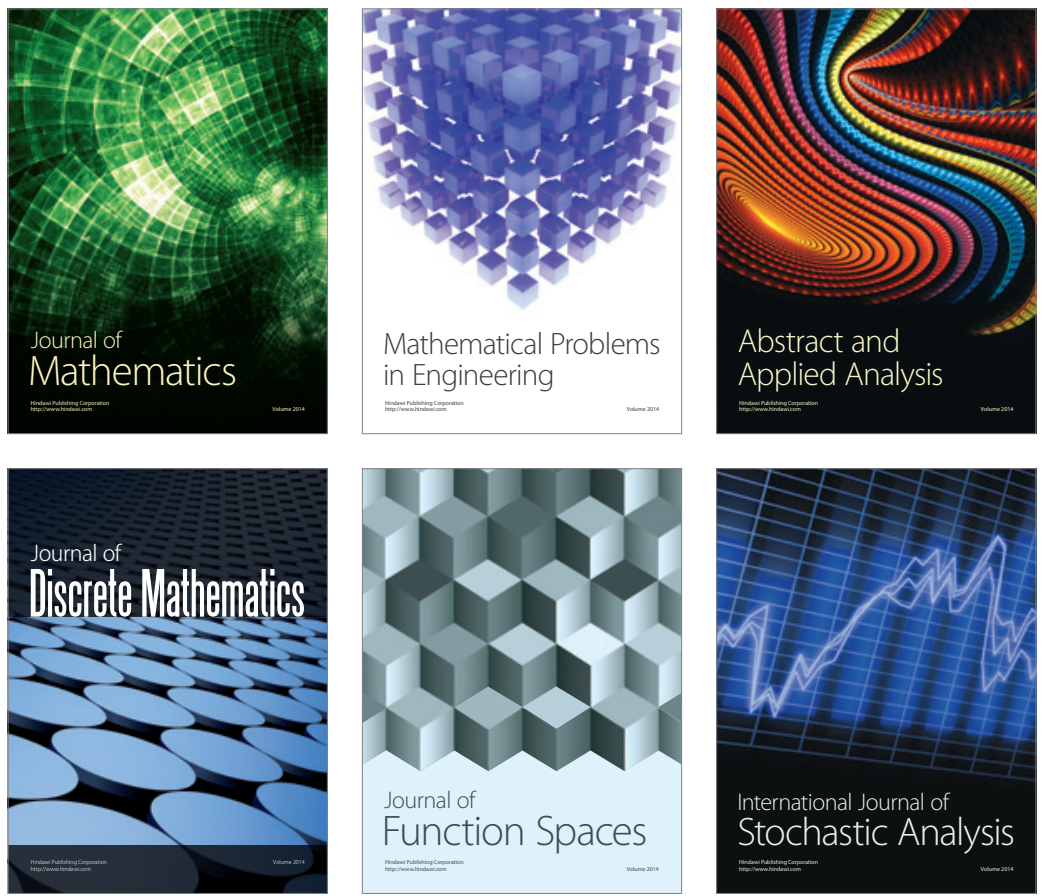

Journal of

Function Spaces

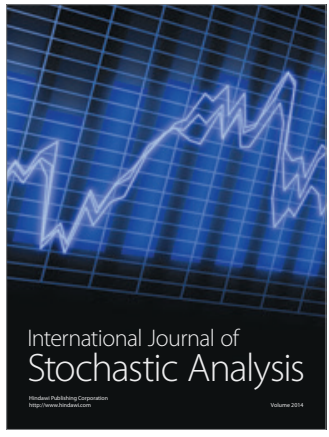

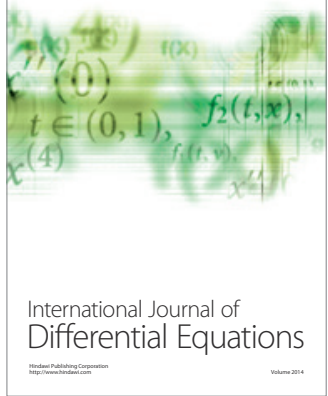
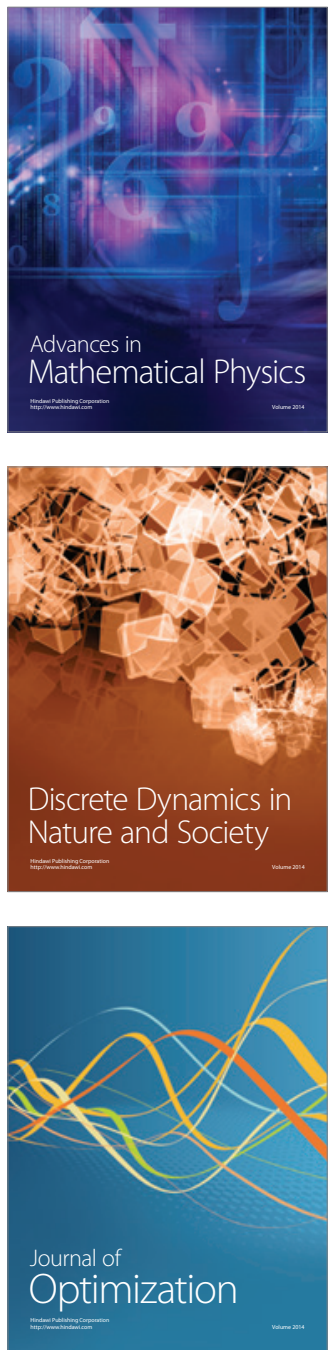